\title{
Determinants of Coronary Heart Disease Incidence among Indonesian Hajj Pilgrims Hospitalized in Saudi Arabia in 2019
}

\author{
Juniarty Naim ${ }^{1 \star}$, Wahiduddin Wahiduddin ${ }^{1}$, Masni Masni ${ }^{2}$, Ridwan Amiruddin ${ }^{1}$, Irwandy Irwandy ${ }^{3}$, M. Nadjib Bustan ${ }^{4}$ \\ ${ }^{1}$ Department of Epidemiology, Faculty of Public Health, Hasanuddin University, Makassar, Indonesia; ${ }^{2}$ Department of \\ Biostatistics, Faculty of Public Health, Hasanuddin University, Makassar, Indonesia; ${ }^{3}$ Department of Hospital Administration, \\ Faculty of Public Health, Hasanuddin University, Makassar, Indonesia; ${ }^{4}$ Department of Statistics, Faculty of Mathematics and \\ Natural Sciences, Universitas Negeri Makassar, Makassar, Indonesia
}

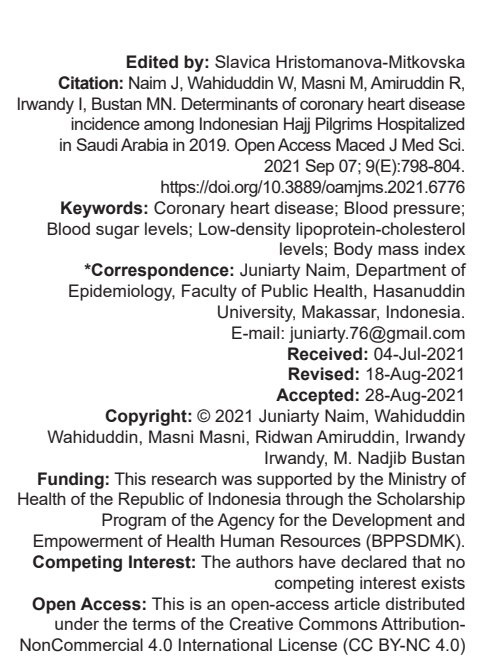

Introduction

The Hajj pilgrimage is worship full of rituals that require sufficient physical strength to carry out. Unlike other obligatory worship, this worship is only required for those who can afford it (istithaah) once in a lifetime. Istithaah includes financial ability, security, and physical or health capabilities [1].

Haij rituals including Tawaf (going around the Kaaba 7 rounds), Sa'ee (walking back and forth from Safa and Marwah 7 times), Stoning of the devil (throw seven pebbles at each of the three pillars in Mina, Jamarāt), and reached on foot the tent to the throwing Jamarāt. Furthermore, Saudi Arabia's extreme natural conditions are not a problem for pilgrims with excellent health conditions. However, most pilgrims, including Indonesian, mostly over 40 years old with comorbidities, significantly affect the health of the pilgrims [2], [3].

Various studies on Haij pilgrims have shown that cardiovascular diseases (CVDs) are the main causes of death for pilgrims, including Indonesian Hajj pilgrims [2],
[4], [5]. Data for Indonesian Hajj pilgrims in 2017-2019 from the Integrated Hajj Computerized System in the Health Sector (Siskohatkes) show that CVDs are the second cause of hospitalization for Hajj pilgrims in Saudi Arabia. Of all CVDs cases hospitalized, coronary heart disease (CHD) is the most common type [3].

From the search for various articles related to Indonesian Hajj pilgrims, we had not found any articles that discuss the determinants of the incidence of $\mathrm{CHD}$ in Indonesian Hajj pilgrims. Therefore, this study aimed to determine the determinants of CHD incidence in Indonesian Hajj pilgrims hospitalized in Saudi Arabia in 2019.

\section{Method}

\section{Samples and design}

This study was an observational analytic study with a case-control design. The study was conducted 
in Makassar using data from the integrated Hajj computerized system in the health sector (siskohatkes) Hajj Health Center (Puskeshaji) in January-June 2021.

The research sample was Indonesian Hajj pilgrims hospitalized in Saudi Arabia in 2019, recorded in the siskohatkes as many as 2749 people. Case samples were Indonesian pilgrims hospitalized in Saudi Arabia with a diagnosis of CHD (ICD X code: I20I25) that met the inclusion criteria. Of the 254 people hospitalized with CHD, 68 people did not meet the criteria, so the case sample was 186 people. The control sample was Indonesian Hajj pilgrims hospitalized in Saudi Arabia with a diagnosis other than CVDs with medical examinations history carried out in Indonesia at least 3 months earlier, only had 1 diagnosis of metabolic disease, and no diagnosis of CHD. This study used a 1:1 comparison between case samples and control samples, so the number of control samples is also 186 people. Controls were selected by matching age and sex with a purposive sampling technique. The inclusion criteria in the control sample were hospitalization in Saudi Arabia with a diagnosis other than heart and blood vessel disease; the data for the variables to be studied were complete in the health care system. Then the exclusion criteria were that there was a diagnosis of ischemic heart disease (120-125) in the record of the results of the second stage of Health examination, having two or more metabolic diseases.

\section{Instrument}

The research instrument was a data collection form, contained identity (serving ID number, age, gender, and occupation), systolic blood pressure (SBP), diastolic blood pressure (DBP), fasting blood glucose (FBG), low-density lipoprotein (LDL)-cholesterol, body mass index (BMI), and smoking behavior. Data were obtained from siskohatkes.

\section{Variables}

The independent variables were education, high blood pressure, high blood sugar levels, high LDLcholesterol levels, excess BMI, and smoking behavior. The dependent variable was the incidence of $\mathrm{CHD}$. All variables were dichotomous, declared "yes" $\mathrm{CHD}$ if met the case criteria, and "no" CHD if met the control criteria. Education was categorized low if not attending school or only completing junior high school, and high if completing senior high school (SMA), associate degree (D3), bachelor degree (S1), graduate degree (S2), or doctoral degree (S3). The criteria for high blood pressure used the JNC7 criteria [6]: SBP $\geq 140 \mathrm{mmHg}$ or DBP $\geq 90 \mathrm{mmHg}$. The criteria for high blood sugar levels used the WHO criteria, FBG $\geq 126 \mathrm{mg} / \mathrm{dl}$ [7]. The criteria for high LDL-cholesterol levels were referred to the NCEP ATP III criteria, $\geq 130 \mathrm{mg} / \mathrm{dl}$ [8]. Excess BMl criteria used the American Heart Association (AHA) criteria, BMI $\geq 25 \mathrm{~kg} / \mathrm{m}^{2}$ [9]. It was, furthermore, categorized as smoking if still smoked or had a history of smoking before.

\section{Data analysis}

Processing and analyzing data were using the Stata version 12 program. The analysis included univariate, bivariate, and multivariate analysis. The risk of the independent variable was assessed by the odds ratio $(\mathrm{RO})$, and its significance was assessed from the 95\% confidence index $(\mathrm{Cl})$. Bivariate analysis using uji Chi-square and OR and multivariate analysis was using a multiple logistic regression test.

\section{Results}

Table 1 shows that most respondents were 65 years, and it decreases in the younger age group. In the case and control groups, the youngest age was 45 years, while the oldest age in the case group was 107 years and in the control group was 93 years. The number of male respondents was much more than the number of female respondents, about $61.83 \%$. Most respondents in the cases group were civil servants (19.89\%), while in the control group was housewives, about $20.97 \%$. Most respondents' education was in elementary school, about $31.99 \%$.

Table 1: Distribution of respondent characteristics on Indonesian Hajj pilgrims who were hospitalized in Saudi Arabia in 2019

\begin{tabular}{|c|c|c|c|c|c|c|}
\hline \multirow[t]{3}{*}{ Characteristic } & \multicolumn{4}{|c|}{ Status respondent } & \multirow{2}{*}{\multicolumn{2}{|c|}{ Total $(n=372)$}} \\
\hline & \multicolumn{2}{|c|}{ Cases $(n=186)$} & \multicolumn{2}{|c|}{ Control $(n=186)$} & & \\
\hline & $\mathrm{n}$ & $\%$ & $\mathrm{n}$ & $\%$ & $\mathrm{n}$ & $\%$ \\
\hline \multicolumn{7}{|l|}{ Age groups (Years) } \\
\hline $45-54$ & 25 & 13.44 & 25 & 13.44 & 50 & 13.44 \\
\hline $55-64$ & 71 & 38.17 & 71 & 38.17 & 142 & 38.17 \\
\hline$\geq 65$ & 90 & 48.39 & 90 & 48.39 & 180 & 48.39 \\
\hline \multicolumn{7}{|l|}{ Sex } \\
\hline Male & 115 & 61.83 & 115 & 61.83 & 230 & 61.83 \\
\hline Female & 71 & 38.17 & 71 & 38.17 & 142 & 38.17 \\
\hline \multicolumn{7}{|l|}{ Job } \\
\hline Civil Servants & 37 & 19.89 & 29 & 15.59 & 66 & 17.74 \\
\hline TNI/POLRI & 1 & 0.54 & 2 & 1.08 & 3 & 0.81 \\
\hline BUMN/BUMD employees & 3 & 1.61 & 3 & 1.61 & 6 & 1.61 \\
\hline Private employees & 31 & 16.67 & 32 & 17.2 & 63 & 16.94 \\
\hline Merchants & 23 & 12.37 & 21 & 11.29 & 44 & 11.83 \\
\hline Farmer & 30 & 16.13 & 43 & 23.12 & 73 & 19.62 \\
\hline Housewife & 36 & 19.35 & 42 & 22.58 & 78 & 20.97 \\
\hline Retired & 25 & 13.44 & 14 & 7.53 & 39 & 10.48 \\
\hline \multicolumn{7}{|l|}{ Education } \\
\hline Elementary school & 57 & 30.65 & 62 & 33.33 & 119 & 31.99 \\
\hline Junior High School & 30 & 16.13 & 20 & 10.75 & 50 & 13.44 \\
\hline Senior High School & 13 & 6.99 & 22 & 11.83 & 35 & 9.41 \\
\hline Diploma & 30 & 16.13 & 15 & 8.06 & 45 & 12.1 \\
\hline Bachelor & 46 & 24.73 & 61 & 32.8 & 107 & 28.76 \\
\hline Magister & 7 & 3.76 & 2 & 1.08 & 9 & 2.42 \\
\hline Doctor & 1 & 0.54 & 1 & 0.54 & 2 & 0.54 \\
\hline Etc & 2 & 1.08 & 3 & 1.61 & 5 & 1.34 \\
\hline
\end{tabular}

Table 2 shows that in the $45-54$ years age group, male respondents reached $84 \%$ (5 times that of female respondents). However, with increasing age, the incidence of CHD in women was increasing. Hence, at 65 years old, although the number of male respondents was still more than female respondents, the difference was only about $10 \%$. 
Table 2: Distribution of respondent age groups by gender in Indonesian hajj pilgrims who were hospitalized in Saudi Arabia in 2019

\begin{tabular}{|c|c|c|c|c|c|c|}
\hline \multirow{3}{*}{$\begin{array}{l}\text { Age groups } \\
\text { (Years) }\end{array}$} & \multicolumn{4}{|l|}{ Sex } & \multirow{2}{*}{\multicolumn{2}{|c|}{ Total $(\mathrm{n}=372)$}} \\
\hline & \multicolumn{2}{|c|}{ Male } & \multicolumn{2}{|c|}{ Female } & & \\
\hline & $\mathrm{n}$ & $\%$ & $\mathrm{n}$ & $\%$ & $n$ & $\%$ \\
\hline $45-54$ & 42 & 84 & 8 & 16 & 50 & 100 \\
\hline $55-64$ & 88 & 61.97 & 54 & 38.03 & 142 & 100 \\
\hline$\geq 65$ & 100 & 55.56 & 80 & 44.44 & 180 & 100 \\
\hline Total & 230 & 61.83 & 142 & 38.17 & 372 & 100 \\
\hline
\end{tabular}

Tables 3 that education and smoking were not significant risk factors for CHD incidence with $p<0.05$. Furthermore, multivariate analysis is choosing a variable with a $p<0.25$ in order to obtain four variables that meet the requirements based on the results of Table 3 , namely, high blood pressure, high blood sugar level, high LDL-cholesterol level, and excess BMI.

Table 3: Bivariate analysis of risk factors for the incidence of CHD in Indonesian hajj pilgrims who were hospitalized in Saudi Arabia in 2019

\begin{tabular}{|c|c|c|c|c|c|c|}
\hline \multirow[t]{3}{*}{ Independent Variable } & \multicolumn{4}{|c|}{ Status respondent } & \multirow[t]{3}{*}{ Odds ratio } & \multirow[t]{3}{*}{$95 \% \mathrm{Cl}$} \\
\hline & \multicolumn{2}{|c|}{ Case $(n=186)$} & \multicolumn{2}{|c|}{ Control $(n=186)$} & & \\
\hline & $\bar{N}$ & $\%$ & $\mathrm{n}$ & $\%$ & & \\
\hline \multicolumn{7}{|l|}{ Education } \\
\hline Low & 89 & 47.85 & 85 & 45.7 & \multirow[t]{2}{*}{1.09} & \multirow[t]{2}{*}{$0.711-1.673$} \\
\hline High & 97 & 52.15 & 101 & 54.3 & & \\
\hline \multicolumn{7}{|l|}{ High blood pressure } \\
\hline Yes & 97 & 52.15 & 60 & 32.26 & \multirow[t]{2}{*}{2.29} & \multirow[t]{2}{*}{$1.471-3.567$} \\
\hline No & 89 & 47.85 & 126 & 67.74 & & \\
\hline \multicolumn{7}{|l|}{ High blood sugar level } \\
\hline Yes & 40 & 21.51 & 23 & 12.37 & \multirow[t]{2}{*}{1.94} & \multirow[t]{2}{*}{$1.074-3.564$} \\
\hline No & 146 & 78.49 & 163 & 87.63 & & \\
\hline \multicolumn{7}{|c|}{ High LDL-cholesterol levels } \\
\hline Yes & 72 & 38.71 & 45 & 24.19 & \multirow[t]{2}{*}{1.99} & \multirow[t]{2}{*}{$1.237-3.177$} \\
\hline No & 114 & 61.29 & 141 & 75.81 & & \\
\hline \multicolumn{7}{|l|}{ Execs BMI } \\
\hline Yes & 72 & 38.71 & 49 & 26.34 & \multirow[t]{2}{*}{1.76} & \multirow[t]{2}{*}{$1.112-2.812$} \\
\hline No & 114 & 61.29 & 137 & 73.66 & & \\
\hline \multicolumn{7}{|l|}{ Smoking } \\
\hline Yes & 35 & 18.82 & 35 & 18.82 & \multirow[t]{2}{*}{1} & \multirow[t]{2}{*}{$0.575-1.740$} \\
\hline No & 151 & 81.18 & 151 & 81.18 & & \\
\hline
\end{tabular}

However, high blood pressure, high blood sugar levels, high LDL-cholesterol levels, and excess $\mathrm{BMI}$ were significant risk factors for $\mathrm{CHD}$ incidence. A person with high blood pressure, after justified, had a risk of suffering from CHD 2.32 times than those without high blood pressure $(\mathrm{RO}=2.32,95 \% \mathrm{Cl}=$ 1.504-3.571). Meanwhile, a person with high blood sugar levels, after justified, had a 1.9 times greater chance of experiencing CHD events than without high blood sugar levels $(\mathrm{RO}=1.90,95 \% \mathrm{Cl}=1.063-$ 3.398). Likewise, after justification, samples with high LDL-cholesterol levels had a 1.82-times risk of developing $\mathrm{CHD}$ compared to those who were not high $(\mathrm{RO}=1.82,95 \% \mathrm{Cl}=1.146-2.879)$. Likewise, after justification, someone with an excess BMI had a risk of suffering from CHD 1.7 times greater than without an excess $\mathrm{BMI}(\mathrm{RO}=1.70,95 \% \mathrm{Cl}=1.073-$ 2.679) (Table 4).

Table 4: Multivariate test results on the incidence of coronary heart disease in Indonesian pilgrims who were hospitalized in Saudi Arabia in 2019

\begin{tabular}{llllll}
\hline Independent variable & Coefficient & Odds ratio & $\mathrm{p}>|\mathrm{z}|$ & \multicolumn{2}{c}{$95 \%$ Conf. interval } \\
\cline { 5 - 6 } & & & & $\mathrm{LL}$ & $\mathrm{UL}$ \\
\hline High blood pressure & 0.841 & 2.32 & $<0.001$ & 1.504 & 3.571 \\
High blood sugar level & 0.642 & 1.90 & 0.030 & 1.063 & 3.398 \\
High LDL-cholesterol level & 0.597 & 1.82 & 0.011 & 1.146 & 2.879 \\
Excess BMI & 0.528 & 1.70 & 0.024 & 1.073 & 2.679 \\
Constanta & -0.818 & 0.441 & 0.000 & 0.3078 & 0.6328 \\
\hline
\end{tabular}

A logistic equation can be made with a multiple logistic regression test to calculate the probability of someone experiencing CHD. Based on the coefficient values and constant values obtained, as listed in Table 4, the following logistic equation was obtained:

$$
\begin{aligned}
& Y=-0.818+0.84_{(\text {high blood pressure) }}+0.64_{\text {(high blood }}+0.53_{(\text {Excess BMI) }} \\
& +0.60_{\text {(high LDL-cholesterol) }}+0.04 \text { sugar levels) }
\end{aligned}
$$

If the four risk factors were owned, then the value of $Y=1.792$ was obtained. Thus the probability could be calculated using the formula:

$$
\begin{gathered}
P=1 /\left(1+\exp ^{(-y)}\right) \\
P=0.8569
\end{gathered}
$$

Based on the results of these calculations, the probability of the incidence of CHD in samples with high blood pressure, high blood sugar levels, high LDLcholesterol, and excess BMI was $85.69 \%$.

\section{Discussion}

The Framingham Heart Study (FHS), first published in 1957, is a pioneer of epidemiological research that introduced the concept of risk factors in CHD. FHS shows the relationship between smoking, blood pressure, and cholesterol levels with CHD incidence [10]. Thousands of subsequent studies increasingly reveal the secret of this disease. However, until now, CVDs remain the main cause of death worldwide.

Age, gender, family history of CVDs, high blood pressure, high blood sugar levels, high blood cholesterol levels, obesity, lack of physical activity, smoking, and socioeconomic status were risk factors for CVDs [11]. The increased risk of CVDs, including $\mathrm{CHD}$, is in line with increasing age, 45 years in men and 55 years in women [12]. The same illustration was seen in this study, where the youngest respondent's age was 45 years, and the percentage increased with age. This is in line with the previous studies. A meta-analysis of 18 cohort studies in the past 50 years showed that without the risk of high blood pressure, high blood sugar levels, hypercholesterolemia, and smoking: Developing CVDs continued to increase with age, starting at age 55 [13].

Males have a greater risk of developing $\mathrm{CHD}$ than females. Estrogen is a hormone that has a protective effect against CHD. Estrogen lowers blood pressure, increases HDL cholesterol levels, and lowers triglyceride levels. Although males own this hormone, the amount is minimal compared to females. This is why females are 7-10 years slower to develop $\mathrm{CHD}$, why postmenopausal females have almost the same risk of $\mathrm{CHD}$ as males, and why females who experience premature menopause have a greater $\mathrm{CHD}$ risk than females with menopause at an older 
age [12], [14], [15], [16]. The difference was also clear; males were more likely to experience $\mathrm{CHD}, 61.83 \%$ of the total respondents. In the age group of 45-54 years, the proportion of males was substantial, about $84 \%$. With increasing age, the difference decreases where at the age of 65 years, males were $55.56 \%$, and females were $44.44 \%$. A review of articles conducted by Gao et al. showed that although the incidence of CVDs is lower in females, the prognosis is worse, and the mortality is higher [15]. Therefore, females should remain cautious and start a healthy lifestyle at a young age.

Socioeconomic factors, in this case, education and wealth, have been proven to be risk factors for CHD. A study conducted in 20 countries with high, middle, and low economic levels showed that low education was associated with lower wealth, having a greater risk of developing CHD than higher education [17]. An article review of several studies of social economy risk factors concluded that the low socioeconomic relationship with $\mathrm{CHD}$ was related to dietary factors. The quality and variety of diet follow the economic level. In low socioeconomic status, the diet is dominated by high glycemic index foods, lack of fiber, and fruit, which causes obesity and even high blood sugar levels [18]. Other studies have shown that educational factors are associated with delays in obtaining health services, suitable for patients with CHD [19]. Research conducted in Indonesia based on 2013 Riskesdas data is also in line with these various studies. Low education is 1.48 times more likely to suffer from $\mathrm{CHD}$ than higher education [20].

In contrast to the various studies above, the results of statistical tests in this study indicated that education was not a risk factor for CHD events. This is in line with the research of $\mathrm{Xu}$ and colleagues, who also found that education was not a risk factor for CHD [21]. Hajj is a mandatory worship for Muslims that requires the ability (isthithaah), including an economic perspective. The pilgrimage to Mecca requires a large amount of money; because of that, almost all pilgrims have economic advantages, so even though their education is low, their socioeconomic status is not.

High blood pressure is the most significant risk factor for CHD. Several pathophysiological mechanisms are the reason for CHD, such as endothelial dysfunction, atherosclerosis, left ventricular enlargement, microcirculation abnormalities, insulin resistance, and sympathetic activation. These mechanisms lead to an imbalance between the supply and demand for oxygen to the heart muscle, which results in ischemia of the heart muscle [22]. This study found that high blood pressure was the most significant variable as a risk factor for $\mathrm{CHD}(\mathrm{RO}=2.32,95 \% \mathrm{IK})=$ 1.504-3.571). These results align with various CHD risk factors studies, including a study in Indonesia in 2016; a patient with high blood pressure had a 5.7 times risk of experiencing CHD. Besides, a study in India in 2017 , where a person with high blood pressure had a 5-fold risk of developing $\mathrm{CHD}$ compared to those without high blood pressure. Similarly, a cohort study conducted over 20 years in Japan showed similar results; patients with a history of high blood pressure had 1.63 times the risk of suffering from CHD [23], [24], [25].

The pathophysiological process of $\mathrm{CHD}$ in diabetics is very complex. Everything is triggered by insulin resistance which causes an increase in insulin in the blood resulting in hyperglycemia. On the other hand, people with high blood sugar levels also experience an imbalance in lipid metabolism and immune response. Combining these three causes may increase oxidative stress, activation of protein kinase $C$, and the production of advanced glycation end products (AGEs) that trigger vascular endothelial dysfunction. This dysfunction causes blood vessels to experience vasoconstriction, chronic inflammation, and thrombus formation (thrombogenesis). This is the cause of atherosclerosis in diabetic patients [26].

The results of statistical tests in this study showed that the respondent's history of high blood sugar levels increased the risk of CHD by 1.9 times (after controlling for other variables). The results of this test are in line with a meta-analysis of 37 cohort studies published between 1966 and 2005, which showed that the incidence of fatal $\mathrm{CHD}$ in people with high blood sugar levels was 5 times higher than in those without high blood sugar levels [27]. In Indonesia, Riskesdas data of 2013 are also in line with this research indicates that a person with high blood sugar levels has a 7.75 times more risk of suffering from $\mathrm{CHD}$ than those without high blood sugar levels [20].

The role of LDL-cholesterol as a risk factor for CHD has been known for a long time, as evidenced by various epidemiological studies on CHD risk factors and various studies that prove that reducing LDLcholesterol levels is very significant in reducing the risk of CHD [28]. An increase in LDL cholesterol is the same as elevated blood pressure and blood sugar levels, causing endothelial dysfunction. The process begins with the formation of fatty streaks on the walls of blood vessels. Oxidized LDL-C, together with proteoglycans and immune complexes, form lipid peroxides and facilitate the accumulation of cholesterol esters and stimulate the proliferation of macrophages present in the lesion. As the atherosclerotic plaque thickens, the arterial walls respond by gradually expanding to maintain the diameter of the vessel lumen. This condition, coupled with metalloproteinases produced by macrophages, makes the plaque prone to rupture and detachment. When plaque is released, then clogs one of the heart's blood vessels, CHD occurs [29].

The statistical tests in this study indicated that a person with a history of high LDL cholesterol levels might have a 1.8 times greater risk of suffering from CHD (after justification) than without a history of high LDL cholesterol levels. These results are in line with the finding of Shen Gao and Lin Jiu from the Department of 
Epidemiology, Beijing An Zhen Hospital, who conducted a review of several journals related to the relationship of circulating oxidized LDL with CVDs. Most of these journals mention that circulating oxidized LDL increases the risk of myocardial infarction and other CHD caused by atherosclerosis. Similarly, a study conducted by Jessica Schubert and colleagues aims to see the effect of decreasing LDL-cholesterol levels on the incidence of $\mathrm{CHD}$ in a person with a history of myocardial infarction, where a decrease in LDL-cholesterol significantly reduces the risk of experiencing CHD and death [30], [31].

Obesity increases CVDs through several mechanisms, such as ectopic lipid deposition, hyperglycemia, and clot formation. Obesity causes adipose tissue dysfunction leading to chronic inflammation contributing to multiple cardiometabolic diseases [32]. This study indicated that excess BMI (after controlling for other variables) increased the risk of CHD 1.7 times compared to without excess BMI. Various studies show similar results. A prospective cohort study conducted in 8 European countries on 7637 CHD cases followed for 12.2 years (median) showed that the risk of CHD was higher in individuals with excess BMI and waist circumference [33]. Similarly, a meta-analysis of 16 prospective cohort studies in the United States and Europe involving 120,813 adults aged over 35 years and followed up for an average of 10.7 years showed that a person's risk for developing multiple cardiometabolic disease (at least two diseases: CHD, stroke, and type 2 DM) increased with increasing BMI. The increased risk ranges from doubling in overweight to 15-fold in someone with obesity [34].

The causal relationship between smoking and CHD is well known. Smoking is responsible for $18 \%$ of deaths caused by CHD. The mechanism of $\mathrm{CHD}$ in smokers through several mechanisms, including inflammation, vasoconstriction, formation of blood clots, and reduced oxygen supply to the heart. In addition to causing direct damage to the heart's blood vessels, smoking also increases levels of oxidized LDL-cholesterol and reduces the benefits of $\mathrm{HDL}$ cholesterol. The risk of damage to the cardiovascular system caused by smoking depends on the duration of smoking and the number and types of cigarettes smoked [35]. The results of statistical tests in this study indicated that smoking was not a risk factor for the incidence of CHD in Indonesian Hajj pilgrims hospitalized in Saudi Arabia. The data obtained from siskohatkes comes from interviews with Hajj pilgrims during the second stage of health checks in Indonesia. There was no explanation obtained by the researcher whether the answer to the smoking question or not was a condition at the time of the examination or whether it included a previous smoking history.

The limitation of this study was the usage of secondary data; no interviews were conducted to confirm or justify the researcher's results. The implication or strength of the results of this study is that it is known that the waiting time for Indonesian Hajj pilgrims is very long, namely there is a waiting time of up to 30 years. This waiting time can be used to carry out prevention and control programs for risk factors for $\mathrm{CHD}$ so that it can reduce the mortality rate of pilgrims from CVDs.

\section{Conclusion}

High blood pressure, high blood sugar levels, high LDL-cholesterol levels, and excess BMI were risk factors for the incidence of $\mathrm{CHD}$ in Indonesian Hajj pilgrims hospitalized in Saudi Arabia in 2019. High blood pressure was the most common risk factor among the four risk factors and most influential on $\mathrm{CHD}$ incidence. The probability of experiencing $\mathrm{CHD}$ after having the four risk factors at the same time was about $85.69 \%$.

\section{Research Ethics}

This research obtained an ethics-free certificate from the Faculty of Public Health, Hasanuddin University.

\section{Acknowledgments}

Our gratitude goes to the Minister of Health of the Republic of Indonesia for the opportunity to continue education with the BPPSDMK scholarship program and the Head of the Hajj Health Center of the Ministry of Health of the Republic of Indonesia for the permission and access to Siskohatkes.

\section{References}

1. Sarwat A. Ensiklopedia Fikih Indonesia 6: Haji Dan Umrah $1^{\text {st }}$ ed. Jakarta: Gramedia Pustaka Utama; 2019. p. 1-426.

2. Al Shimemeri A. Cardiovascular disease in Hajj pilgrims. J Saudi Heart Assoc 2012;24:123-7. https://doi.org/10.1016/j. jsha.2012.02.004

3. Pusat Kesehatan Haji Kemenkes RI. Siskohatkes Shar'i. Porta Siskohatkes; 2020. Available from: https://www.siskohatkes. 
kemkes.go.id. [Last accessed on 2020 Feb 06].

4. Qamariah H. Angka kematian Jemaah Haji Indonesia. Media Health Res Dev. 2001;11:44-50.

5. Pane M, Imari S, Alwi Q, Nyoman Kandun I, CookAR, Samaan G. Causes of mortality for Indonesian hajj pilgrims: Comparison between routine death certificate and verbal autopsy findings. PLoS One. 2013;8(8):1-7. https://doi.org/10.1371/journal. pone.0073243

PMid:23991182

6. Unger T, Borghi C, Charchar F, Khan NA, Poulter NR, Prabhakaran D. 2020 International society of hypertension global hypertension practice guidelines. Hypertension. 2020;75(6):133457. https://doi.org/10.1161/hypertensionaha.120.15026

7. World Health Organization, International Diabetes Federation. Definition and Diagnosis of Diabetes Mellitus and Intermediate Hyperglycaemia: Report of a WHO/IDF Consultation. Geneva: World Health Organization; 2006. p. 1-50. Available from: http:// www.who.int/diabetes/publications/diagnosis_diabetes2006/en. [Last accessed on 2021 Aug 19].

8. National Institute of Health ATP III. ATP III Guidelines At-AGlance Quick Desk Reference. United States: National Institute of Health, Department of Health and Human Services; 2001. p. 1-6.

9. Powell-Wiley TM, Poirier P, Burke LE, Després JP, GordonLarsen P, Lavie CJ. Obesity and cardiovascular disease: A scientific statement from the American heart association. Circulation. 2021;143(21):e984-1010.

PMid:33882682

10. Hajar R. Risk factors for coronary artery disease: Historical perspectives. Heart Views. 2017;18(3):109-14. https://doi. org/10.4103/heartviews.heartviews_106_17 PMid:29184622

11. Mendis S, Puska P, Norrving B, editor. Global Atlas on Cardiovascular Disease Prevention and Control. Geneva: World Health Organization; 2011.

12. Amani R, Sharifi N. In: Gaze D, editor. Cardiovascular Disease Risk Factors, the Cardiovascular System Physiology, Diagnostics and Clinical Implications. India: InTech; 2012. p. 279-310. https://doi.org/10.5772/34374

13. Berry JD, Dyer A, Cai X, Garside DB, Ning H, Thomas A. Lifetime risks of cardiovascular disease. $\mathrm{N}$ Engl J Med. 2012;366(4):321-9.

PMid:22276822

14. Maas $A H$, Appelman YE. Gender differences in coronary heart disease. Neth Heart J. 2010;18(12):598-603. https://doi. org/10.1007/s12471-010-0841-y

PMid:21301622

15. Gao Z, Chen Z, Sun A, Deng X. Gender differences in cardiovascular disease. Med Nov Technol Devices. 2019;4:100025.

16. Zhu D, Chung H, Dobson AJ, Pandeya N, Giles GG, Bruinsma F. Articles age at natural menopause and risk of incident cardiovascular disease : A pooled analysis of individual patient data. Lancet Public Health. 2019;4(11):553-64. PMid:31588031

17. Rosengren A, Smyth A, Rangarajan S, Ramasundarahettige C, Bangdiwala SI, AlHabib KF. Socioeconomic status and risk of cardiovascular disease in 20 low-income, middle-income, and high-income countries: The prospective urban rural epidemiologic (PURE) study. Lancet Glob Health. 2019;7(6):e748-60. https:// doi.org/10.1016/s2214-109x(19)30045-2

18. Psaltopoulou T, Hatzis G, Papageorgiou N, Androulakis E, Briasoulis A, Tousoulis D. Socioeconomic status and risk factors for cardiovascular disease: Impact of dietary mediators. Hellenic J Cardiol. 2017;58(1):32-42. https://doi.org/10.1016/j.

\section{hjc.2017.01.022}

PMid:28161284

19. Farshidi H, Rahimi S, Abdi A, Salehi S, Madani A. Factors associated with pre-hospital delay in patients with acute myocardial infarction. Iran Red Crescent Med J. 2013;15(4):3126. https://doi.org/10.5812/ircmj.2367

20. Ghani L, Susilawati MD, Novriani H. Faktor risiko dominan penyakit jantung koroner di Indonesia. Bul Penelit Kesehat. 2016;44(3):153-64. https://doi.org/10.22435/bpk. v44i3.5436.153-164

21. Xu J, Lee ET, Peterson LE, Devereux RB, Rhoades ER, Umans JG. Differences in risk factors for coronary heart disease among diabetic and nondiabetic individuals from a population with high rates of diabetes: The strong heart study. J Clin Endocrinol Metab. 2012;97(10):3766-74. https://doi. org/10.1210/jc.2012-2110

PMid:22802089

22. Escobar E. Hypertension and coronary heart disease. J Hum Hypertens. 2002;16(1):S61-3.

PMid:11986897

23. Nelwan EJ, Widjajanto E, Andarini S, Djati MS. Modified risk factors for coronary heart disease (CHD) in Minahasa ethnic group from Manado city Indonesia. J Exp Life Sci. 2016;6(2):8894. https://doi.org/10.21776/ub.jels.2016.006.02.06

24. Biswas A, Singh SK, Singh RK. Linkages between hypertension and coronary heart disease in India: Evidence from India human development survey-2 (2011-2012). Indian J Community Med. 2017;42(4):200-3. https://doi.org/10.4103/ijcm.ijcm_168_16 PMid:29184318

25. Matsunaga M, Yatsuya $\mathrm{H}$, Iso $\mathrm{H}$, Yamashita K, Li Y, Yamagishi $\mathrm{K}$. Similarities and differences between coronary heart disease and stroke in the associations with cardiovascular risk factors: The Japan collaborative cohort study. Atherosclerosis. 2017;261:12430. https://doi.org/10.1016/j.atherosclerosis.2017.03.003 PMid:28292514

26. Severino P, D'Amato A, Netti L, Pucci M, De Marchis $M$, Palmirotta R. Diabetes mellitus and ischemic heart disease: The role of ion channels. Int J Mol Sci. 2018;19(3):802. https://doi. org/10.3390/ijms19030802

PMid:29534462

27. Huxley R, Barzi F, Woodward M. Excess risk of fatal coronary heart disease associated with diabetes in men and women: Meta-analysis of 37 prospective cohort studies. $\mathrm{Br}$ Med J. 2006;332(7533):73-6. https://doi.org/10.1136/ bmj.38678.389583.7c

PMid: 16371403

28. Hermida N, Balligand JL. Low-density lipoprotein-cholesterolinduced endothelial dysfunction and oxidative stress: The role of statins. Antioxid Redox Signal. 2014;20(8):1216-37. https:// doi.org/10.1089/ars.2013.5537

PMid:23924077

29. Chilton RJ. Pathophysiology of coronary heart disease: A brief review. J Am Osteopath Assoc. 2004;104(9):7-10. PMid: 15467017

30. Gao S, Liu J. Association between circulating oxidized low-density lipoprotein and atherosclerotic cardiovascular disease. Chronic Dis Transl Med. 2017;3(2):89-94. https://doi. org/10.1016/j.cdtm.2017.02.008

PMid:29063061

31. Schubert J, Lindahl B, Melhus $H$, Renlund $H$, Leosdottir $M$, Yari A. Low-density lipoprotein cholesterol reduction and statin intensity in myocardial infarction patients and major adverse outcomes: A Swedish nationwide cohort study. Eur Heart J. 2021;42(3):243-52. https://doi.org/10.1093/eurheartj/ehaa1011

32. Nakamura K, Fuster JJ, Walsh K. Adipokines: A link between 
obesity and cardiovascular disease. J Cardiol. 2014;63(4):250-9. PMid:24355497

33. Lassale C, Tzoulaki I, Moons KG, Sweeting M, Boer J, Johnson L. Separate and combined associations of obesity and metabolic health with coronary heart disease: A pan-European case-cohort analysis. Eur Heart J. 2018;39(5):397-406.

PMid:29020414

34. Kivimäki M, Kuosma E, Ferrie JE, Luukkonen R, Nyberg ST, Alfredsson L. Overweight, obesity, and risk of cardiometabolic multimorbidity: Pooled analysis of individual-level data for 120813 adults from 16 cohort studies from the USA and Europe. Lancet Public Health. 2017;2(6):e277-85. https://doi. org/10.1016/s2468-2667(17)30074-9

PMid:28626830

35. Puig-Cotado F, Tursan d'Espaignet E, St Claire S, Bianco E, Bhatti L, Schotte K. Tobacco and Coronary Heart Disease: WHO Tobacco Knowledge Summaries. Geneva: World Health Organization; 2020. 